\title{
Endoscopic ultrasound-guided radiofrequency ablation for management of gastric gastrointestinal stromal tumor
}

A 56-year-old man presented with abdominal pain and dyspepsia. On upper digestive endoscopy, a submucosal lesion was found in the distal gastric lesser curvature, but no conclusive diagnosis could be achieved with conventional biopsies. Endoscopic ultrasound (EUS) showed a $12 \times 7 \mathrm{~mm}$ well-defined, homogeneous, hypoechoic nodule without signs of infiltration into the muscularis propria, suggestive of benign gastrointestinal stromal tumor (GIST) ( $\mathbf{F i g . 1}$ ). Fine-needle aspiration with a 22-gauge needle (Expect; Boston Scientific, Marlborough, Massachusetts, USA) was performed, confirming a low risk GIST. Histopathological examination revealed a GIST presenting less than 5 mitoses per high-power field.

The patient rejected surgical treatment, so we proposed EUS-guided radiofrequency ablation (RFA) ( Video 1 ). We punctured the lesion with an 18-gauge EUS-RFA electrode needle connected to a radiofrequency generator (VIVA-RF generator; STARme, Seoul, South Korea), and applied ablative radiofrequency four times (50 W for 10 seconds).

EUS follow-up was performed after 4 weeks, and showed a slight mural thickening of the muscularis propria and submucosal layers; the lesion itself could not

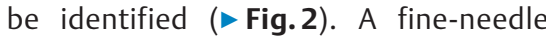
biopsy with 22-gauge histological needle (Acquire; Boston Scientific) was performed and confirmed the absence of GIST-type mesenchymal structures. A second EUS 6 months later confirmed eradication of the lesion, and showed a well-preserved layer pattern ( $\mathbf{F i g . 3}$ ).

Guidelines recommend radical surgical resection with a clear margin (R0) as the gold standard for localized primary GIST [1]. Although endoscopic resection of GISTs has been reported [2], it is not supported by current guidelines because of the low rate of successful $\mathrm{R} 0$ resections achieved [1]. RFA uses high frequency alternating current applied via an elec-
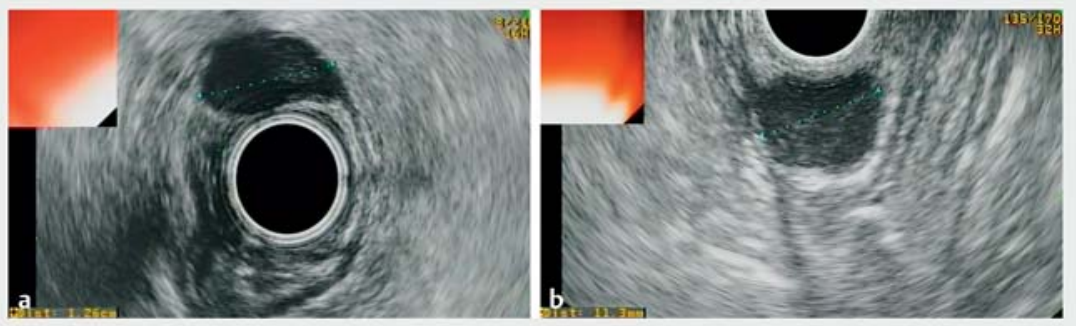

- Fig. 1 Endoscopic ultrasound image of gastrointestinal stromal tumor. a Radial view. b Linear view.

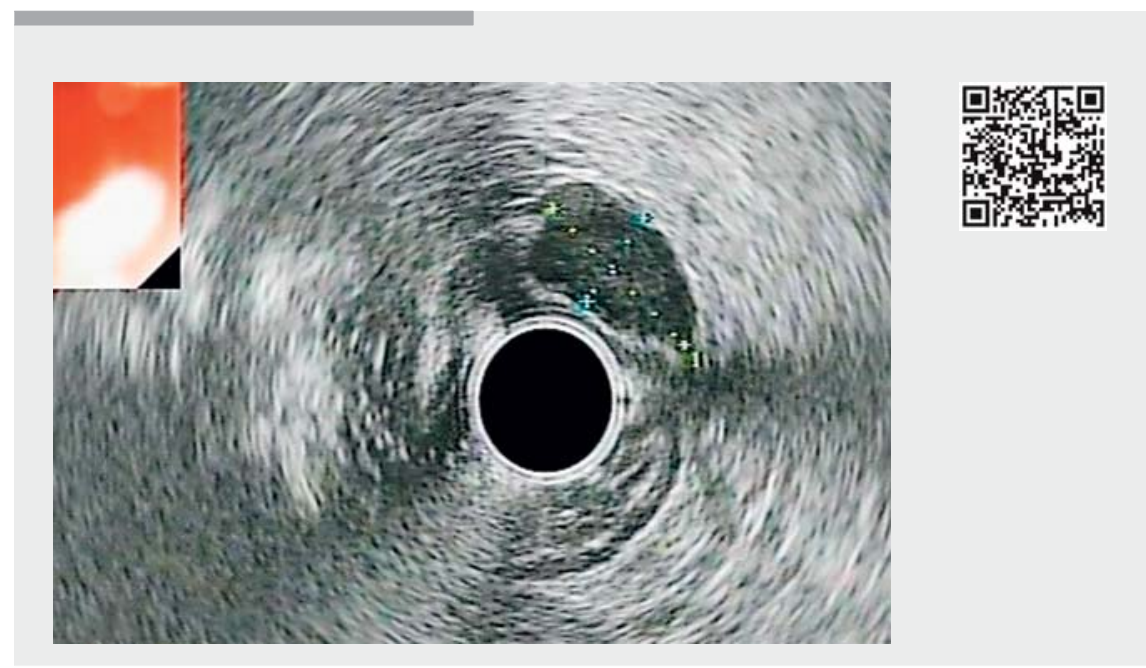

$\checkmark$ Video 1 Diagnosis of benign gastrointestinal stromal tumor (GIST) and treatment with endoscopic ultrasound (EUS)-guided radiofrequency ablation (RFA). EUS follow-up was performed after 4 weeks, and showed a slight mural thickening of the muscularis propria and submucosal layers, while the lesion itself could not be identified. A second EUS 6 months later confirmed eradication of the lesion, and showed a well-preserved layer pattern.

trode to generate localized areas of coagulative necrosis and tissue desiccation $[3,4]$. Although it is usually applied percutaneously or laparoscopically, successful outcomes of EUS-guided RFA using an 18-gauge needle for benign and malignant pancreatic lesions have been reported recently [5]. To our knowledge, this is the first report of a successful ablative radiofrequency therapy of a gastric GIST.
Endoscopy_UCTN_Code_TTT_1AS_2AB

Competing interests

None 

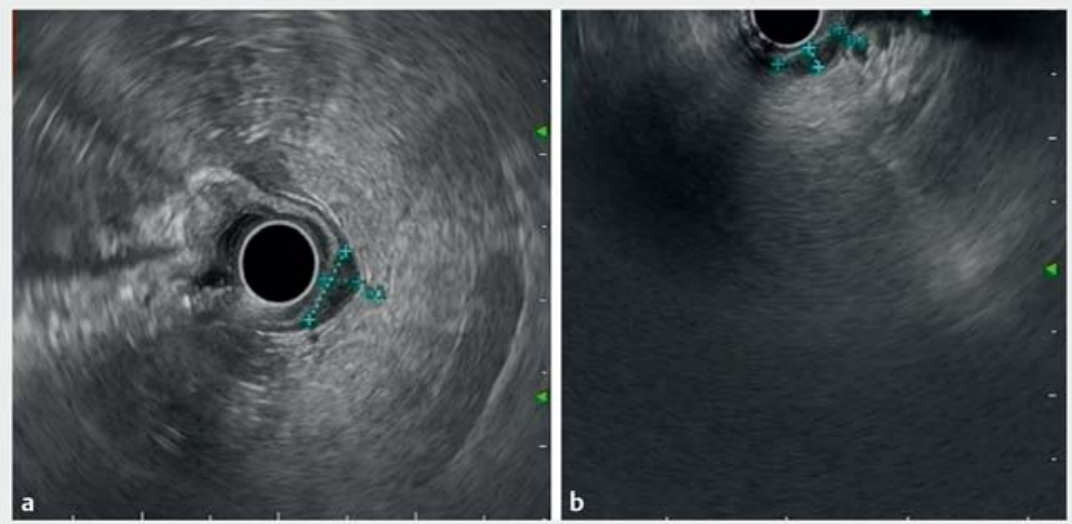

- Fig. 2 Endoscopic ultrasound image of gastrointestinal stromal tumor after treatment with ablative radiofrequency. a Radial view. b Linear view.

The authors

Sergio Bazaga Pérez de Rozas, Mario Alberto Gallardo Ramírez, Francisco Javier GarcíaAlonso, Ana Yaiza Carbajo, Manuel PérezMiranda Castillo, Carlos de la Serna Higuera Gastroenterology and Hepatology Department, Hospital Universitario Rio Hortega, Valladolid, Spain

\section{Corresponding author}

\section{Sergio Bazaga Pérez de Rozas, MD}

Digestive Endoscopy Unit, Hospital

Universitario Río Hortega, Calle Dulzaina, 2,

47012 Valladolid, Spain

Fax: +34-983-420400

sergio.bpr@gmail.com

\section{References}

[1] Poveda A, García del Muro X, López-Guerrero JA et al. GEIS guidelines for gastrointestinal sarcomas (GIST). Cancer Treat Rev 2017; 55: 107 -119

[2] Mosquera-Klinger G, de la Serna Higuera C, Pérez-Miranda M. Treatment of gastric GIST using endoscopic techniques combined with the application of endoloop and intralesional cyanoacrylate in a non-surgical patient. Rev Esp Enferm Dig 2018; 110: 825

[3] Song TJ, Seo DW, Lakhtakia S et al. Initial experience of EUS-guided radiofrequency ablation of unresectable pancreatic cancer. Gastrointest Endosc 2016; 83: 440 - 443

[4] Yoon IS, Shin JH, Han K et al. Ultrasoundguided intraoperative radiofrequency ablation and surgical resection for liver metastasis from malignant gastrointestinal stromal tumors. Korean J Radiol 2018; 19: 54-62

[5] Crinò SF, D’Onofrio M, Bernardoni L et al. EUS-guided radiofrequency ablation (EUSRFA) of solid pancreatic neoplasm using an 18-gauge needle electrode: feasibility, safety, and technical success. J Gastrointest Liver Dis 2018; 27: 67-72

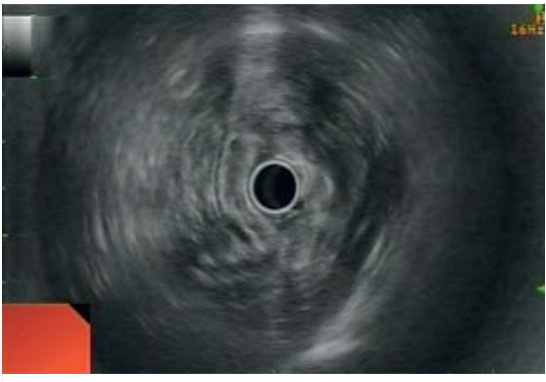

Fig. 3 Endoscopic ultrasound 6 months later confirmed eradication of the lesion, and showed a preserved layer pattern.
Bibliography

DOI https://doi.org/10.1055/a-0885-9752

Published online: 2.5.2019

Endoscopy 2019; 51: E223-E224

(c) Georg Thieme Verlag KG

Stuttgart · New York

ISSN 0013-726X

\section{ENDOSCOPY E-VIDEOS}

https://eref.thieme.de/e-videos

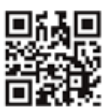

Endoscopy E-Videos is a free access online section, reporting on interesting cases and new

techniques in gastroenterological endoscopy. All papers include a high quality video and all contributions are freely accessible online.

This section has its own submission website at

https://mc.manuscriptcentral.com/e-videos 